\title{
Awareness Level about Breast Cancer Risk Factors, Barriers, Attitude and Breast Cancer Screening among Indonesian Women
}

\author{
Solikhah Solikhah ${ }^{1 *}$, Supannee Promthet ${ }^{2,3}$, Cameron Hurst ${ }^{4}$
}

\begin{abstract}
Background: Globally, breast cancer is the second most common cancer in women and is a leading cause of mortality in Indonesia. Raising awareness of breast cancer is particularly important to help at risk women seek medical treatment for this disease. This study aimed to comprehensively investigate the Indonesian women's level of knowledge about breast cancer risk factors, barriers, attitude and breast cancer screening. Methods: This population-based cross-sectional study administered the breast cancer awareness Indonesian scale (BCAS-I) to 856 Indonesian women. Samples were selected in rural and urban combinations from three provinces by stratified random sampling. The ordinal logistic model was used to investigate the clustering effect of the participant's characteristics in this study. Results: Of the women, $62 \%$ lived in rural areas and 38\% lived in urban areas. Living in an urban area was significantly associated with a lower knowledge of the risk factors. However, living in an urban area was significantly associated with better attitudes and healthier behaviours related to breast cancer awareness. Women with higher education levels had $70 \%$ worse attitudes toward breast cancer awareness. Women living South of Sumatera, women living in Yogyakarta, and unmarried women were $5.03,3.84$, and 1.56 times as likely to have higher perceived barriers, respectively. Conclusion: Urban women had a poorer level of knowledge of breast cancer risk factors compared to women living in more rural areas. The result of this study may reflect inadequate breast cancer awareness campaigns or a lack of breast cancer awareness campaigns. These findings suggest that additional education programs aiming to increase awareness and educate the public are needed.
\end{abstract}

Keywords: Breast cancer- breast cancer screening- Indonesian women

Asian Pac J Cancer Prev, 20 (3), 877-884

\section{Introduction}

Breast cancer has become an increasing concern and is a major global public health burden. Malignancy of the breast has been reported to be the second leading cause of cancer, accounting for $25 \%$ of all new cancer cases among women across the world in 2012 (Ferlay et al., 2015). Additionally, breast cancer has the highest incidence in women in low and middle-income countries. The increasing incidence of breast cancer in economically developing countries is likely influenced by lifestyle changes and growing urbanization (Jemal et al., 2011). More importantly, breast cancer is known to be the leading cause of cancer deaths in women in many Asian countries (Kimman et al., 2012). In Indonesia, a low and middle income countries, breast cancer is the most commonly diagnosed cancer in women (Kimman et al., 2012; Youlden et al., 2014). The late presentation of breast cancer is thought to contribute to its poor prognosis and high mortality rates (Youlden et al., 2014; Liu et al., 2014).

Mammography screening is now well established and recommended by the World Health Organization (2015). This method is considered to be cost-effective and feasible in countries that have a good health infrastructure in place. However, in Indonesia as well as in other low and middle income countries, where the healthcare infrastructure is not as well established, most women do not undergo routine mammography due to limited or no access to mammography facilities. Raising awareness of breast cancer is particularly important to encourage at risk women to become familiar with any changes they may detect during 'self-examination' of the breast. Thus, in countries such as Indonesia, breast cancer awareness is likely properly implemented in the limited health care setting (Bhikoo et al., 2011; Bray et al., 2012; Youlden et al., 2014).

${ }^{1}$ Faculty of Public Health, Universitas Ahmad Dahlan, Yogyakarta, Indonesia, ${ }^{2}$ Department of Epidemiology and Biostatistics, Faculty of Public Health, ${ }^{3}$ ASEAN Cancer Epidemiology and Prevention Research Group, Khon Kaen University, Khon Kaen, ${ }^{4}$ Biostatistics Center of Excellence, Faculty of Medicine, Chulalongkorn University, Bangkok, Thailand. *For Correspondence: solikhah@ikm.uad.ac.id 
Several epidemiologic studies have assessed breast cancer awareness in various populations. The majority of previous studies have demonstrated that the level of awareness is low in some Western (Linsell et al., 2008) and Asian countries (Tazhibi and Feizi, 2014; Elobaid et al., 2014). This low level of awareness and knowledge of risk factors for breast cancer as well as the various screening methods was more commonly seen among those women with lower education levels (Hvidberg et al., 2014). Other factors contributing to the lack of awareness include limited health education programs especially for women living more rural areas (Norlaili et al., 2013; Tazhibi and Feizi, 2014; Gupta et al., 2015), isolated areas, and in regions with an inadequate health care infrastructure (Akram et al., 2017; Kisiangani et al., 2018).

Although some studies have examined the level of breast cancer awareness in Western (Linsell et al., 2008), Asian (Liu et al., 2014; Tazhibi and Feizi, 2014; Elobaid et al., 2014; Al-Sharbatti et al., 2014) and African countries (Sambanje and Mafuvadze, 2012; Suh et al., 2012), these studies were conducted on more focused and specific populations. Despite the use of validated measures, these measures were not specific for breast cancer. To the best of our knowledge, assessing the level of breast cancer awareness using validated measures remains largely unexplored in population-based samples in Asian countries, such as Indonesia. Therefore, the purpose of conducting a large population-based survey among Indonesian women was to comprehensively assess the level of breast cancer awareness in relation to risk factors, barriers, attitudes, and health behaviours related to breast cancer screening.

\section{Materials and Methods}

\section{Study design and participants}

This population-based cross-sectional study was conducted among 856 Indonesian women ages 18 to 80 years old from March-May 2016. The sample population was invited to complete the BCAS-I using a self-administered questionnaire. All participants were selected from a combination of rural and urban backgrounds, from three provinces-Yogyakarta, South of Sumatera, and East Nusa Tenggara, using a stratified random sampling method. The province and location area participants were then combined to represent the spectrum of cultures, religions, and socio-economic backgrounds, in addition to the incidence rate of breast cancer, in Indonesia that based on the research of Oemiati et al., (2011). Our sample size was recommended by Comrey and Lee (1992) where $n=50$ is considered very poor, $n=100$ is considered poor, $\mathrm{n}=200$ is considered fair, $\mathrm{n}=300$ is considered good, $\mathrm{n}=500$ is considered very good, and $\mathrm{n}=1000$ or more is considered excellent (Comrey and Lee, 1992). Furthermore, participants in this study were literate in the Indonesian language with no previous history of breast cancer and were neither pregnant nor breastfeeding. A total of 856 Indonesian women, out of 871 Indonesian women enrolled, responded to this survey for a completion rate of $98.28 \%$.

\section{Ethical consideration}

Oral and written approval for our study was obtained from the Khon Kaen University Ethics Committee for Human Research (reference number: HE582369), based on the Declaration of Helsinki and the ICH Good Clinical Practice Guidelines. Consent was also obtained from all individuals participating in this study as well as written permission from The Indonesian Ministry of Home Affairs (No.440.02/1085/Polpum).

\section{Study instrument and variable assessment}

This study used a validated measure of the BCAS-I. The process for establishing the BCAS-I is described in more detail by Solikhah et al., (2017). In brief, items were developed in English (Rakkapao et al., 2016) and then translated into Indonesian using a forward and backward translation method, as recommended by the World Health Organization (2015). Twenty Indonesian women participated in a pilot study to ensure that face validity was established and that each participant understood each item in the questionnaire.

The questionnaire was comprised of questions pertaining to knowledge of risk factors ( 9 items), knowledge of signs and symptoms ( 8 items), attitudes toward breast cancer prevention ( 6 item), barriers to breast cancer screening (4 items), and health behaviours related to breast cancer awareness ( 8 items). Knowledge of breast cancer was assessed using a categorical response scale (yes/don't know/no). Participants answered items on a five-point Likert-type scale, ranging from 1 to 5 in attitude and barrier domains ( $1=$ strongly disagree, $2=$ disagree, 3 = neutral, $4=$ agree, and $5=$ strongly agree). Lastly, a 5-point frequency scale rated behaviour related to the breast cancer awareness sub-scale.

The questionnaire also asked about the following variables: age (measured continuously), monthly income (measured continuously), province (South of Sumatera, Yogyakarta, or East Nusa Tenggara), locale (rural or urban), education level (measured as binary), marital status (single, married, or widowed/separated/divorced), religion (Muslim, Christian, or other), current occupation (unemployed, farmer, trader, labourer, or government/ official/enterprise/business), health insurance (yes/no), tobacco use (yes/no), and alcohol use (yes/no).

\section{Statistical analyses}

Descriptive statistics for continuous variables were expressed as the mean \pm standard deviation to illustrate participant characteristics. Frequencies and percentages were used to summarize the categorical variables. The five outcomes of this study were based on five BCAS-I domains: knowledge of risk factors, knowledge of signs and symptoms, attitudes toward breast cancer prevention, barriers to breast cancer screening, and health behaviours related to breast cancer awareness.

The five outcomes of this study were categorized as "high", "moderate", and "low" for each of the five outcomes pertaining to each studied domain of the BCAS-I based on the pattern of relationships among a set of an observed category. Individuals who were 
classified as similar to each other were grouped into latent classes. Other covariates were included to obtain a correlation with additional adjusted variables for each observed variable. The effects of demographic characteristics were then investigated using ordinal logistic model. The demographic characteristics were: age (categorized by decade), monthly income province (treated as a continuous variable), province (South of Sumatera, Yogyakarta, or East Nusa Tenggara), locale (rural or urban), education level (binary), marital status (single, married, or widowed/separated/divorced), religion (Muslim, Christian, or other), current occupation (no employment, farmer, trader, labourer, or government/ official/enterprise/business), and health insurance (yes/ no). This ordinal logistic mixed model approach was used to address any effects of covariates that might have occurred. Potential bias that may have been introduced by missing values in the dataset was also evaluated using multiple iterative regression imputations. Any missing values were gauged by comparing the difference between the magnitude of effects in the complete case and computed data analyses.

Crude (bivariate analysis) and adjusted odds ratios with $95 \%$ confidence intervals $(\mathrm{CI})$ and $\mathrm{P}$ values were used to represent the associations between demographic characteristics and BCAS-I items. All of the data analyses were conducted using R CRAN version 3.3.1 (2015) and the R library lme4 (Rosseel, 2012) was used for mixed modelling.

\section{Results}

The mean (SD) age for the Indonesian women was 30 (11) and the age range was 18 to 80 years old. A higher percentage of participants lived in rural areas $(n=530$, $62 \%)$ than in urban areas $(n=325,38 \%)$. Many women reported a low income $(n=647,75.6 \%)$ and many did not have health insurance $(\mathrm{n}=519,60.6 \%)$. The participant characteristics are presented in Table 1.

The results of the bivariate and multivariate ordinal logistic regression models are presented in Tables 2, 3, 4 and 5 . The crude and adjusted odds ratios for knowledge of breast cancer risk factors are presented in Table 2. After adjusting for other covariates using multivariate ordinal logistic regression model, living in an urban area was significantly associated with knowledge of risk factors, with the odds of better knowledge of breast cancer risk factors decreasing by $31 \%$ (ORadj $=0.69,95 \% \mathrm{CI}$ : $0.51-0.93, \mathrm{p}<0.05)$. Additionally, Table 3 shows that these women had 1.39 times the odds of higher levels of attitudes toward breast cancer prevention (ORadj = 1.39, 95\% CI: $1.02-1.89, \mathrm{p}<0.05$ ); and Table 5 shows that these women had 1.40 times the odds of higher levels of health behaviours related to breast cancer awareness $(\mathrm{ORadj}=1.40,95 \% \mathrm{CI}: 1.02-1.91, \mathrm{p}<0.05)$. However, there is no evidence to suggest the odds of better knowledge of signs and symptoms of breast cancer.

Table 3 presents the relationship between the studied determinants and the level of attitude towards breast cancer prevention. For example, relatives of those with
Table 1 Participant Characteristics (Total Number of Subject $=856$ )

\begin{tabular}{|c|c|c|}
\hline Characteristics & Number & $\begin{array}{c}\text { Mean (SD) or } \\
\text { number }(\%)\end{array}$ \\
\hline Age & & $30(11)$ \\
\hline \multicolumn{3}{|l|}{ Province } \\
\hline Yogyakarta & 194 & 22.7 \\
\hline East Nusa Tenggara & 255 & 29.8 \\
\hline South of Sumatera & 407 & 47.5 \\
\hline \multicolumn{3}{|l|}{ Locale } \\
\hline Rural & 530 & 62 \\
\hline Urban & 326 & 38 \\
\hline \multicolumn{3}{|l|}{ Education level } \\
\hline Primary school & 66 & 7.7 \\
\hline Junior high school & 57 & 6.7 \\
\hline Senior high school & 326 & 38.1 \\
\hline Bachelor's degree & 380 & 44.3 \\
\hline Postgraduate degree & 27 & 3.2 \\
\hline \multicolumn{3}{|l|}{ Marital status } \\
\hline Single & 426 & 49.8 \\
\hline Married & 399 & 46.6 \\
\hline Widowed/separated/discovered & 31 & 3.6 \\
\hline \multicolumn{3}{|l|}{ Monthly income } \\
\hline $\begin{array}{l}\text { Lower income group }<2,000,000 \mathrm{IDR}^{*} \\
\left(<152 \mathrm{USD}^{* *}\right)\end{array}$ & 647 & 75.6 \\
\hline $\begin{array}{l}\text { Middle income group } 2,000,000 \text { to } \\
6,000,000 \text { IDR ( } 152 \text { to } 457 \text { USD) }\end{array}$ & 198 & 23.1 \\
\hline $\begin{array}{l}\text { High income group } \geq 6,000,000 \text { IDR } \\
\text { ( } \geq 457 \text { USD) }\end{array}$ & 11 & 1.3 \\
\hline \multicolumn{3}{|l|}{ Religion } \\
\hline Muslim & 584 & 68.2 \\
\hline Christian & 262 & 30.6 \\
\hline Other & 10 & 1.2 \\
\hline \multicolumn{3}{|l|}{ Occupation } \\
\hline Unemployment (includes housewives) & 287 & 33.5 \\
\hline Farmer & 47 & 5.5 \\
\hline Trader & 70 & 8.2 \\
\hline Labourer & 96 & 11.2 \\
\hline Government/official/enterprise/business & 181 & 21.1 \\
\hline Student & 148 & 17.3 \\
\hline Other & 27 & 3.2 \\
\hline \multicolumn{3}{|l|}{ Health insurance } \\
\hline Yes & 337 & 39.4 \\
\hline No & 519 & 60.6 \\
\hline
\end{tabular}

*, Indonesian Rupiah Rate; **, United States Dollar

a primary school education or less (the referent group) and those with at least a senior high school education showed a poorer attitude towards breast cancer prevention. Specifically, the odds of those who had completed high school (senior) were 62\% less than women with only a primary school level of education $(\mathrm{ORadj}=0.38,95 \%$ CI: $0.21-0.69, \mathrm{p}<0.01)$. This difference became more pronounced with higher levels of education. Compared to women with a primary school education, women with a bachelor's degree, and women with a postgraduate qualification, on average had $70 \%$ less odds of a better 
Table 2. Crude and Adjusted Odds Ratios for Knowledge of Breast Cancer Risk Factors

\begin{tabular}{|c|c|c|c|}
\hline Effect & Crude OR & Adjusted OR & $95 \% \mathrm{CI}$ \\
\hline Age (in 10 years) & 1 & 1.07 & $0.90-1.28$ \\
\hline Province (ref: East Nusa Tenggara) & $\chi^{2} \mathrm{LRT}=5.56, \mathrm{df}=2, \mathrm{p}=0.062$ & $\chi^{2} \mathrm{LRT}=2.82, \mathrm{df}=2, \mathrm{p}=0.24$ & \\
\hline South of Sumatera & 1.09 & 1.38 & $0.59-3.20$ \\
\hline Yogyakarta & 0.74 & 1.01 & $0.43-2.41$ \\
\hline Locale (ref: urban) & $0.65 * *$ & $0,69^{*}$ & $0.51-0.93$ \\
\hline Education (ref: primary school) & $\chi^{2} \mathrm{LRT}=7.81, \mathrm{df}=4, \mathrm{p}=0.099$ & $\chi^{2} \mathrm{LRT}=3.12, \mathrm{df}=4, \mathrm{p}=0.54$ & \\
\hline Junior high school & 0.85 & 0.8 & $0.42-1.54$ \\
\hline Senior high school & 0.84 & 0.93 & $0.54-1.60$ \\
\hline Bachelor's degree & 0.71 & 0.84 & $0.48-1.48$ \\
\hline Postgraduate degree & $0.34^{*}$ & 0.48 & $0.19-1.20$ \\
\hline Marital status (ref: married) & $\chi^{2} \mathrm{LRT}=0.02, \mathrm{df}=2, \mathrm{p}=0.99$ & $\chi^{2} \mathrm{LRT}=0.11, \mathrm{df}=2, \mathrm{p}=0.95$ & \\
\hline Single & 1.02 & 1.03 & $0.71-1.49$ \\
\hline Widowed/separated/divorced & 1.01 & 0.9 & $0.45-1.82$ \\
\hline $\begin{array}{l}\text { Monthly income (ref: }<2,000,000 \text { IDR } \\
\text { (<152 USD)) }\end{array}$ & $\chi^{2} \mathrm{LRT}=3.59, \mathrm{df}=2, \mathrm{p}=0.166$ & $\chi^{2} \mathrm{LRT}=0.82, \mathrm{df}=2, \mathrm{p}=0.66$ & \\
\hline $\begin{array}{l}2,000,000 \text { to } 6,000,000 \operatorname{IDR}(152 \text { to } 457 \\
\text { USD) }\end{array}$ & 0.77 & 0.89 & $0.62-1.27$ \\
\hline$\geq 6,000,000 \mathrm{IDR}(\geq 457 \mathrm{USD})$ & 0.54 & 0.65 & $0.19-2.25$ \\
\hline Religion (ref: Christian) & $\chi^{2} \mathrm{LRT}=0.93, \mathrm{df}=2, \mathrm{p}=0.63$ & $\chi^{2} \mathrm{LRT}=0.56, \mathrm{df}=2, \mathrm{p}=0.76$ & \\
\hline Muslim & 0.96 & 0.88 & $0.39-1.99$ \\
\hline Other & 0.55 & 0.6 & $0.16-2.31$ \\
\hline Occupation (ref: farmer) & $\chi^{2} \mathrm{LRT}=6.84, \mathrm{df}=6, \mathrm{p}=0.337$ & $\chi^{2} \mathrm{LRT}=3.07, \mathrm{df}=6, \mathrm{p}=0.80$ & \\
\hline Unemployed (includes housewives) & 1.12 & 1.37 & $0.72-2.58$ \\
\hline Trader & 1.34 & 1.52 & $0.74-3.11$ \\
\hline Labourer & 0.9 & 1.17 & $0.58-2.35$ \\
\hline Government/official/enterprise/business & 0.76 & 1.04 & $0.52-2.05$ \\
\hline Student & 1.04 & 1.3 & $0.63-2.67$ \\
\hline Other & 0.9 & 1.26 & $0.47-3.39$ \\
\hline
\end{tabular}

attitude toward breast cancer prevention $(\mathrm{ORadj}=0.30$, 95\% CI: $0.17-0.56, \mathrm{p}<0.001)$. This pattern was also found in relation to the effect of education level on health behaviours related to breast cancer awareness (Table 5).

The effects of participant demographics on the level of barriers to breast cancer screening are presented in Table 4. East Nusa Tenggara province was considered as the province reference category. South of Sumatera and Yogyakarta had 5.03 and 3.84 higher odds, respectively, of barriers to breast cancer screening (ORadj South of Sumatera $=5.03,95 \%$ CI: $2.09-12.09, \mathrm{p}<0.001$; ORadj Yogyakarta $=3.84,95 \%$ CI: $1.57-9.43, p<0.01)$. Single women were marginally aware $(\mathrm{ORadj}=1.56,95 \% \mathrm{CI}$ : $1.07-2.28, \mathrm{p}<0.001)$.

When participants with differing levels of education (primary school, junior high school, senior high school, bachelor's degree, and postgraduate degree) were pooled, there was little evidence to conclude that education level had any effect on the odds of better health behaviours for breast cancer awareness (Table 5). This pattern was also observed for the middle-income group and likely educational level, with the odds of higher health behaviour related to breast cancer awareness decreasing by $31 \%($ ORadj $=0.69,95 \%$ CI: $0.47-0.99, \mathrm{p}<0.05)$. Additionally, women who were trade workers had a significantly higher odds of better health behaviour $($ ORadj $=2.35,95 \%$ CI: $1.11-4.95, \mathrm{p}<0.05)$.

\section{Discussion}

Increasing breast cancer awareness, which is particularly important in low and middle-income countries such as Indonesia, is an effective and feasible way to increase the number of women who will receive timely clinical breast examinations or mammography. To the best of our knowledge, this is the first study that used validated breast cancer awareness measures in a population-based sample to assess the level of breast cancer awareness and related effects on knowledge of risk factors for breast cancer, knowledge signs and symptoms of breast cancer, attitudes toward breast cancer prevention, barriers to breast cancer screening, and health behaviours related to breast cancer awareness, in a large sample of Indonesian women. An increasing level of awareness in economically developing countries is likely as women become familiar with any changes in their breasts that may contribute 
Table 3. Crude and Adjusted Odds Ratios for Attitude Toward Breast Cancer Prevention

\begin{tabular}{|c|c|c|c|}
\hline Effect & Crude OR & Adjusted OR & $95 \% \mathrm{CI}$ \\
\hline Age (in 10 years) & 1.12 & 1.06 & $0.88-1.26$ \\
\hline Province (ref: East Nusa Tenggara) & $\chi^{2} \mathrm{LRT}=4.13, \mathrm{df}=2, \mathrm{p}=0.13$ & $\chi^{2} \mathrm{LRT}=0.64, \mathrm{df}=2, \mathrm{p}=0.73$ & \\
\hline South of Sumatera & 1.31 & 0.81 & $0.35-1.84$ \\
\hline Yogyakarta & 1.37 & 0.73 & $0.31-1.71$ \\
\hline Locale (ref: urban) & 1.27 & $1.39 *$ & $1.02-1.89$ \\
\hline Education (ref: primary school) & $\chi^{2} \mathrm{LRT}=39.85, \mathrm{df}=4, \mathrm{p}=0.001^{* * *}$ & $\chi^{2} \mathrm{LRT}=28.37, \mathrm{df}=4, \mathrm{p}=0.001 * * *$ & \\
\hline Junior high school & 0.75 & 0.81 & $0.40-1.64$ \\
\hline Senior high school & $0.39^{* * *}$ & $0.38^{* *}$ & $0.21-0.69$ \\
\hline Bachelor's degree & $0.30 * * *$ & $0.30 * * *$ & $0.17-0.56$ \\
\hline Postgraduate degree & $0.11 * * *$ & $0.11 * * *$ & $0.04-0.29$ \\
\hline Marital status (ref: married) & $\chi^{2} \mathrm{LRT}=0.78, \mathrm{df}=2, \mathrm{p}=0.68$ & $\chi^{2} \mathrm{LRT}=3.24, \mathrm{df}=2, \mathrm{p}=0.20$ & \\
\hline Single & 0.9 & 1.31 & $0.90-1.90$ \\
\hline Widowed/separated/divorced & 0.86 & 0.65 & $0.30-1.39$ \\
\hline $\begin{array}{l}\text { Monthly income (ref: }<2,000,000 \\
\text { IDR (<152 USD)) }\end{array}$ & $\chi^{2} \mathrm{LRT}=4.09, \mathrm{df}=2, \mathrm{p}=0.13$ & $\chi^{2} \mathrm{LRT}=0.26, \mathrm{df}=2, \mathrm{p}=0.88$ & \\
\hline $\begin{array}{l}2,000,000 \text { to } 6,000,000 \text { IDR(152 to } \\
457 \text { USD) }\end{array}$ & $0.74 *$ & 0.91 & $0.64-1.31$ \\
\hline$\geq 6,000,000 \mathrm{IDR}(\geq 457 \mathrm{USD})$ & 0.73 & 0.92 & $0.29-2.96$ \\
\hline Religion (ref: Christian) & $\chi^{2} \mathrm{LRT}=5.89, \mathrm{df}=2, \mathrm{p}=0.05$ & $\chi^{2} \mathrm{LRT}=0.95, \mathrm{df}=2, \mathrm{p}=0.62$ & \\
\hline Muslim & $1.41^{*}$ & 1.46 & $0.66-3.25$ \\
\hline Other & 1.27 & 1.5 & $0.42-5.42$ \\
\hline Occupation (ref: farmer) & $\mathrm{X}^{2} \mathrm{LRT}=18.68, \mathrm{df}=6, \mathrm{p}=0.005^{* * *}$ & $\chi^{2} \mathrm{LRT}=8.63, \mathrm{df}=2, \mathrm{p}=0.20$ & \\
\hline Unemployed (includes housewives) & 0.81 & 1.08 & $0.55-2.09$ \\
\hline Trader & 1.79 & 1.99 & $0.93-4.29$ \\
\hline Labourer & 0.75 & 0.95 & $0.46-1.96$ \\
\hline $\begin{array}{l}\text { Government/official/enterprise/ } \\
\text { business }\end{array}$ & 0.64 & 1.19 & $0.59-2.41$ \\
\hline Student & 0.63 & 0.92 & $0.44-1.94$ \\
\hline Other & 0.47 & 0.67 & $0.25-1.78$ \\
\hline
\end{tabular}

to early diagnosis of this disease. A poorer level of understanding of risk factors and screening methods seems to lead to women rarely or never checking their breasts. Additionally, early diagnosis of breast cancer is known to reduce breast cancer mortality rates (Renganathan et al., 2014).

Our findings showed that awareness about breast cancer risk factors was poor among women from urban areas. Only $31 \%$ of women from urban areas had knowledge of well-known risk factors for breast cancer, many women in urban areas had lower income levels. Although other studies have consistently found poor knowledge of risk factors among Asian women (Tazhibi and Feizi, 2014; Islam et al., 2016) as well as among British women (Linsell et al., 2008), the current study showed an even poorer level of knowledge. A poorer awareness level of breast cancer risk factors seems to lead to difficulties in the recognition of breast cancer symptoms, a greater disease severity and more advanced stages of disease due to a longer time period before help is sought.

The attitudes and health behaviours related to breast cancer among women living in urban areas were higher compared to women living in rural areas. However, an inadequate level of knowledge of breast cancer risk factors was found for urban women. Our findings emphasize that knowledge does not always translate into changed attitudes and behaviours. Our findings contrast with findings from a sample of Malaysian women, which indicated that inadequate knowledge about risk factors translated into poor attitudes and behaviours (Subramanian et al., 2013). Our findings can likely be attributed to ineffective awareness campaigns that inadequately advised women about maintaining a healthy lifestyle and about breast cancer screening methods. Thus, it is important to identify and educate the public about the associated risk factors for breast cancer so that individuals can incorporate sustainable attitudes and lifestyle changes (Alharbi et al., 2012).

Furthermore, participants who were unmarried and who lived in the South of Sumatera and Yogyakarta provinces were considered to have greater barriers to breast cancer screening. Higher barriers to breast cancer screening among these women are likely due to a lack 
Table 4. Crude and Adjusted Odds Ratios for Barriers to Breast Cancer Screening

\begin{tabular}{|c|c|c|c|}
\hline Effect & Crude OR & Adjusted OR & $95 \% \mathrm{CI}$ \\
\hline Age (in 10 years) & $1.22 * * *$ & 1.15 & $0.96-1.38$ \\
\hline Province (ref: East Nusa Tenggara) & $\chi^{2} \mathrm{LRT}=50.31, \mathrm{df}=2, \mathrm{p}=0.001 * * *$ & $\chi^{2} \mathrm{LRT}=13.70, \mathrm{df}=2, \mathrm{p}=0.001^{* * *}$ & \\
\hline South of Sumatera & $2.91 * * *$ & $5.03 * * *$ & $2.09-12.09$ \\
\hline Yogyakarta & $2.56^{* * *}$ & $3.84 * *$ & $1.57-9.43$ \\
\hline Locale (ref: urban) & 1.3 & 1.06 & $0.77-1.44$ \\
\hline Education (ref: primary school) & $\chi^{2} \mathrm{LRT}=7.96, \mathrm{df}=4, \mathrm{p}=0.09$ & $\chi^{2} \mathrm{LRT}=8.08, \mathrm{df}=4, \mathrm{p}=0.09$ & \\
\hline Junior high school & 0.78 & 0.8 & $0.41-1.54$ \\
\hline Senior high school & 0.71 & 1.04 & $0.59-1.84$ \\
\hline Bachelor's degree & $0.55^{*}$ & 0.68 & $0.38-1.23$ \\
\hline Postgraduate degree & 0.59 & 0.54 & $0.20-1.42$ \\
\hline Marital status (ref: married) & $\chi^{2} \mathrm{LRT}=4.57, \mathrm{df}=2, \mathrm{p}=0.10$ & $\chi^{2} \mathrm{LRT}=3.97, \mathrm{df}=2, \mathrm{p}=0.05^{*}$ & \\
\hline Single & 0.85 & $1.56^{*}$ & $1.07-2.28$ \\
\hline Widowed/separated/divorced & 0.61 & 1.31 & $0.65-2.64$ \\
\hline $\begin{array}{l}\text { Monthly income (ref: }<2,000,000 \\
\text { IDR ( }<152 \text { USD)) }\end{array}$ & $\chi^{2} \mathrm{LRT}=0.14, \mathrm{df}=2, \mathrm{p}=0.93$ & $\chi^{2} \mathrm{LRT}=0.42, \mathrm{df}=2, \mathrm{p}=0.81$ & \\
\hline $\begin{array}{l}2,000,000 \text { to } 6,000,000 \operatorname{IDR}(152 \\
\text { to } 457 \text { USD })\end{array}$ & 0.95 & 0.89 & $0.62-1.27$ \\
\hline$\geq 6,000,000 \mathrm{IDR}(\geq 457 \mathrm{USD})$ & 0.98 & 0.97 & $0.29-3.32$ \\
\hline Religion (ref: Christian) & $\chi^{2} \mathrm{LRT}=38.99, \mathrm{df}=2, \mathrm{p}=0.001 * * *$ & $\chi^{2} \mathrm{LRT}=3.05, \mathrm{df}=2, \mathrm{p}=0.22$ & \\
\hline Muslim & $2.46^{* * *}$ & 0.5 & $0.21-1.16$ \\
\hline Other & 2.58 & 1.05 & $0.24-4.53$ \\
\hline Occupation (ref: farmer) & $\chi^{2} \mathrm{LRT}=28.47, \mathrm{df}=6, \mathrm{p}=7.65$ & $\chi^{2} \mathrm{LRT}=8.85, \mathrm{df}=6, \mathrm{p}=0.18$ & \\
\hline Unemployed (includes housewives) & 0.91 & 1.16 & $0.61-2.23$ \\
\hline Trader & 1.47 & 1.43 & $0.69-2.97$ \\
\hline Labourer & 1.12 & 1.25 & $0.61-2.54$ \\
\hline $\begin{array}{l}\text { Government/official/enterprise/ } \\
\text { business }\end{array}$ & 1.06 & 1.39 & $0.69-2.78$ \\
\hline Student & $0.44 * *$ & 0.7 & $0.34-1.45$ \\
\hline Other & 1.07 & 1.2 & $0.46-3.14$ \\
\hline
\end{tabular}

of interest, motivation and/or concern for health-related issues. These findings are in line with a previous study that found that unmarried women had a greater number of perceived barriers to breast screening (Tazhibi and Feizi, 2014). Our study findings also indicated that low income was negatively associated with the odds of more health-related behaviours. Additionally, low income was significantly associated with difficulties in seeking breast cancer treatment. Therefore, increasing the perceived barriers among women is thought to have resulted in the awareness of health related behaviour, particularly the presentation for disease diagnosis. Previous studies conducted in developing countries found that the main barrier to adequately achieving early diagnosis and treatment was financial ( Iskandarsyah et al., 2014; Akram et al., 2017; Kisiangani et al., 2018). Previous studies in Indonesia also reported difficulties in seeking medical treatment due to the high economic cost involved (Garg et al., 2010; Iskandarsyah et al., 2014). Furthermore, significant discrepancies between needed and provided information are likely also barriers to breast cancer screening, particularly in provinces such as the South of Sumatera and Yogyakarta. Further barriers to breast cancer screening included ethnicity and socio-economic background (Jack et al., 2014; Okoronkwo et al., 2015).

It is also important that the limitations of this study be highlighted. The data collected were based on self-reported BCAS-I questionnaires. In this situation, it is important to take into account spontaneous responses given as a result of emotional factors. However, the participants were accompanied a researcher to explain any difficulties in the instrument. Additionally, we used a validated instrument with easily-understood language and no personally sensitive questions, so generalization beyond Indonesian women can be assumed.

Despite the limitations present in this study, the study has several major strengths. This is the first study of its kind, conducted using a large population-based sample to measure breast cancer awareness in Indonesian women. Participants who did not have health insurance and who were from low-income groups demonstrated a lower level of knowledge. Surprisingly, these findings were reversed for attitudes and behaviours. Overall, our findings reveal a low level of comprehensive knowledge, attitudes, and behaviours related to breast cancer awareness among Indonesian women in general. 
Table 5. Crude and Adjusted Odds Ratios for Health Behaviours Related to Breast Cancer Awareness

\begin{tabular}{|c|c|c|c|}
\hline Effect & Crude OR & Adjusted OR & $95 \% \mathrm{CI}$ \\
\hline Age (in 10 years) & $1.20 * *$ & 0.95 & $0.80-1.14$ \\
\hline Province (ref: East Nusa Tenggara) & $\chi^{2} \mathrm{LRT}=12.83, \mathrm{df}=2, \mathrm{p}=0.002 * * *$ & $\chi^{2} \mathrm{LRT}=1.35, \mathrm{df}=2, \mathrm{p}=0.51$ & \\
\hline South of Sumatera & 1 & 1.09 & $0.48-2.48$ \\
\hline Yogyakarta & $1.73 * * *$ & 1.36 & $0.58-3.16$ \\
\hline Locale (ref: urban) & $1.31^{*}$ & $1.40^{*}$ & $1.02-1.91$ \\
\hline Education (ref: primary school) & $\chi^{2} \mathrm{LRT}=61.47, \mathrm{df}=4, \mathrm{p}=1.42$ & $\chi^{2} \mathrm{LRT}=33.73, \mathrm{df}=4, \mathrm{p}=0.001 * * *$ & \\
\hline Junior high school & 0.67 & 0.73 & $0.35-1.50$ \\
\hline Senior high school & $0.31 * * *$ & $0.34 * * *$ & $0.18-0.63$ \\
\hline Bachelor's degree & $0.18 * * *$ & $0.21 * * *$ & $0.11-0.40$ \\
\hline Postgraduate degree & $0.14 * * *$ & $0.16^{* * *}$ & $0.06-0.42$ \\
\hline Marital status (ref: married) & $\chi^{2} \mathrm{LRT}=12.42, \mathrm{df}=2, \mathrm{p}=0.002 * * *$ & $\chi^{2} \mathrm{LRT}=1.64, \mathrm{df}=2, \mathrm{p}=0.44$ & \\
\hline Single & $0.73 * *$ & 0.88 & $0.60-1.28$ \\
\hline Widowed/separated/divorced & $2.05 * *$ & 1.51 & $0.71-3.18$ \\
\hline $\begin{array}{l}\text { Monthly income (ref: }<2,000,000 \\
\text { IDR (<152 USD)) }\end{array}$ & $\chi^{2} \mathrm{LRT}=12.97, \mathrm{df}=2, \mathrm{p}=0.002 * * *$ & $\chi^{2} \mathrm{LRT}=4.84, \mathrm{df}=2, \mathrm{p}=0.09$ & \\
\hline $\begin{array}{l}2,000,000 \text { to } 6,000,000 \operatorname{IDR}(152 \\
\text { to } 457 \text { USD) }\end{array}$ & $0.61 * * *$ & $0.69^{*}$ & $0.47-0.99$ \\
\hline$\geq 6,000,000 \mathrm{IDR}(\geq 457 \mathrm{USD})$ & 0.37 & 0.51 & $0.16-1.58$ \\
\hline Religion (ref: Christian) & $\chi^{2} \mathrm{LRT}=1.08, \mathrm{df}=2, \mathrm{p}=0.58$ & $\chi^{2} \mathrm{LRT}=1.27, \mathrm{df}=2, \mathrm{p}=0.53$ & \\
\hline Muslim & 1.14 & 0.63 & $0.29-1.40$ \\
\hline Other & 0.87 & 0.83 & $0.24-2.87$ \\
\hline Occupation (ref: farmer) & $\chi^{2} \mathrm{LRT}=34.21, \mathrm{df}=6, \mathrm{p}=0.001 * * *$ & $\chi^{2} \mathrm{LRT}=10.89, \mathrm{df}=6, \mathrm{p}=0.09$ & \\
\hline Unemployed (includes housewives) & 0.85 & 1.09 & $0.57-2.09$ \\
\hline Trader & $2.38^{*}$ & $2.35 *$ & $1.11-4.95$ \\
\hline Labourer & 1.06 & 1.42 & $0.70-2.88$ \\
\hline $\begin{array}{l}\text { Government/official/enterprise/ } \\
\text { business }\end{array}$ & 0.59 & 1.33 & $0.67-2.65$ \\
\hline Student & 0.59 & 0.84 & $0.41-1.74$ \\
\hline Other & 0.83 & 1.35 & $0.51-3.58$ \\
\hline
\end{tabular}

In conclusion, our study found that women from urban areas had a poorer level of knowledge regarding breast cancer risk factors compared to women living in more rural areas. However, knowledge of the risk factors did not translate into a more positive attitude toward breast cancer prevention and behaviours related to breast cancer awareness. A poorer level of breast cancer awareness may reflect an inadequate breast cancer awareness campaign or a lack of a breast cancer awareness campaign. Additionally, education programs are needed to increase awareness and educate the public. Subsequent assessment to measure the impact of these educational programs is also needed.

\section{Conflicts of interest}

All of the authors declare that they have no conflicts of interest.

\section{Acknowledgments}

This study was granted by The KKU Scholarship for ASEAN and GMS Countries' Personal of Academic Year 2014, Khon Kaen University.

\section{References}

Akram M, Iqbal M, Daniyal M, et al (2017). Awareness and current knowledge of breast cancer. Biol Res, 50, 33 .

Alharbi NA, Alshammari MS, Almutairi BM, et al (2012). Knowledge, awareness, and practices concerning breast cancer among Kuwaiti female school teachers. Alex J Med, 48, 75-82.

Al-Sharbatti SS, Shaikh RB, Mathew E, et al (2014). Assessment of breast cancer awareness among female university students in Ajman, United Arab Emirates. Sultan Qaboos Univ Med, 14, 522-9.

Bhikoo R, Srinivasa S, Yu T-C, et al (2011). Systematic review of breast cancer biology in developing countries (part 2): asian subcontinent and South East Asia. Cancers, 3, 2382-2401.

Bray F, Jemal A, Grey N, et al (2012). Global cancer transitions according to the Human Development Index (2008-2030): a population-based study. Lancet Oncol, 13, 790-801.

Comrey A, Lee H (1992). A first course in factor analysis. Lawrence Erlbaum Associates, pp 299-322.

Elobaid YE, Aw TC, Grivna M, et al (2014). Breast cancer screening awareness, knowledge, and practice among Arab women in the United Arab Emirates: A Cross-Sectional Survey. PLoS One, 9, e105783.

Ferlay J, Soerjomataram I, Dikshit R, et al (2015). Cancer incidence and mortality worldwide: sources, methods and

Asian Pacific Journal of Cancer Prevention, Vol 20 
major patterns in GLOBOCAN 2012. Int J Cancer, 136, 359-86.

Garg P, Bansal M, Garg M, et al (2010). Creating awareness about the painless nature of early breast cancer lump is important in low-income countries. Breast $J, \mathbf{1 6}, 101-2$.

Gupta A, Shridhar K, Dhillon PK (2015). A review of breast cancer awareness among women in India: Cancer literate or awareness deficit?. Eur J Cancer, 51, 2058-66.

Hvidberg L, Pedersen AF, Wulff CN, et al (2014). Cancer awareness and socio-economic position: results from a population-based study in Denmark. BMC Cancer, 14, 2-13.

Iskandarsyah A, De Klerk C, Suardi DR, et al (2014). Psychosocial and cultural reasons for delay in seeking help and nonadherence to treatment in Indonesian women with breast cancer: a qualitative study. Health Psychol, 33, 214-21.

Islam RM, Bell RJ, Billah B, et al (2016). Awareness of breast cancer and barriers to breast screening uptake in Bangladesh: A population based survey. Maturitas, 84, 68-74.

Jack RH, Møller H, Robson T, et al (2014). Breast cancer screening uptake among women from different ethnic groups in London: a population-based cohort study. $B M J$ Open, 4, e005586.

Jemal A, Bray F, Center MM, et al (2011). Global cancer statistics. CA Cancer J Clin, 61, 69-90.

Kimman M, Norman R, Jan S, et al (2012). The burden of cancer in member countries of the Association of Southeast Asian Nations (ASEAN). Asian Pac J Cancer Prev, 13, 411-20.

Kisiangani J, Baliddawa J, Marinda P, et al (2018). Determinants of breast cancer early detection for cues to expanded control and care: the lived experiences among women from Western Kenya. BMC Womens Health, 18, 2-9.

Linsell L, Burgess CC, Ramirez AJ (2008). Breast cancer awareness among older women. Br J Cancer, 99, 1221-5.

Liu L-Y, Wang F, Yu L-X, et al (2014). Breast cancer awareness among women in Eastern China: a cross-sectional study. BMC Public Health, 14, 2-8.

Norlaili AA, Fatihah MA, Daliana NFN, et al (2013). Breast cancer awareness of rural women in Malaysia: is it the same as in the cities?. Asian Pac J Cancer Prev, 14, 7161-4.

Okoronkwo IL, Ejike-Okoye P, Chinweuba AU, et al (2015). Financial barriers to utilization of screening and treatment services for breast cancer: an equity analysis in Nigeria. Niger J Clin Pract, 18, 287-91.

Rakkapao N, Promthet S, Moore MA, et al (2016). Development of a breast cancer awareness scale for Thai women: Moving towards a validated measure. Asian Pac J Cancer Prev, 17, 851-6.

Renganathan L, Ramasubramaniam S, Al-Touby S, et al (2014). What do Omani Women know about Breast Cancer Symptoms?. Oman Med J, 29, 408-13.

Rosseel Y (2012). Lavaan: An R package for structural equation modeling. J Stat Softw, 48, 1-36.

Sambanje MN, Mafuvadze B (2012). Breast cancer knowledge and awareness among university students in Angola. Pan Afr Med J, 11, 1-10.

Solikhah S, Promthet S, Rakkapao N, et al (2017). Validation of an Indonesian version of the breast cancer awareness scale (BCAS-I). Asian Pac J Cancer Prev, 18, 515-22.

Subramanian P, Oranye NO, Masri AM, et al (2013). Breast cancer knowledge and screening behaviour among women with a positive family history: a cross sectional study. Asian Pac J Cancer Prev, 14, 6783-90.

Suh MAB, Atashili J, Fuh EA, et al (2012). Breast self-examination and breast cancer awareness in women in developing countries: a survey of women in Buea, Cameroon. $B M C$ Res Notes, 5, 2-6.
Tazhibi M, Feizi A (2014). Awareness levels about breast cancer risk factors, early warning signs, and screening and therapeutic approaches among Iranian adult women: A large population based study using latent class analysis. BioMed Res Int, 2014, Article ID 306352.

Youlden DR, Cramb SM, Yip CH, et al (2014). Incidence and mortality of female breast cancer in the Asia-Pacific region. Cancer Biol Med, 11, 101-5.

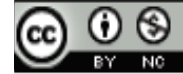

This work is licensed under a Creative Commons AttributionNon Commercial 4.0 International License. 